Louisiana State University

LSU Digital Commons

Faculty Publications

Department of Biological Sciences

$1-1-2014$

\title{
Genetic species delineation among branching Caribbean Porites corals
}

C. Prada

Louisiana State University

M. B. De Biasse

Louisiana State University

J. E. Neigel

University of Louisiana at Lafayette

B. Yednock

University of Louisiana at Lafayette

J. L. Stake

University of Louisiana at Lafayette

See next page for additional authors

Follow this and additional works at: https://digitalcommons.Isu.edu/biosci_pubs

\section{Recommended Citation}

Prada, C., De Biasse, M., Neigel, J., Yednock, B., Stake, J., Forsman, Z., Baums, I., \& Hellberg, M. (2014). Genetic species delineation among branching Caribbean Porites corals. Coral Reefs, 33 (4), 1019-1030. https://doi.org/10.1007/s00338-014-1179-5

This Article is brought to you for free and open access by the Department of Biological Sciences at LSU Digital Commons. It has been accepted for inclusion in Faculty Publications by an authorized administrator of LSU Digital Commons. For more information, please contact ir@lsu.edu. 
Authors

C. Prada, M. B. De Biasse, J. E. Neigel, B. Yednock, J. L. Stake, Z. H. Forsman, I. B. Baums, and M. E. Hellberg 


\title{
Genetic species delineation among branching Caribbean Porites corals
}

\author{
C. Prada $\cdot$ M. B. DeBiasse $\cdot$ J. E. Neigel • \\ B. Yednock $\cdot$ J. L. Stake $\cdot$ Z. H. Forsman . \\ I. B. Baums $\cdot$ M. E. Hellberg
}

Received: 16 December 2013/Accepted: 30 May 2014/Published online: 15 June 2014

(c) Springer-Verlag Berlin Heidelberg 2014

\begin{abstract}
Coral species are difficult to discern because of their morphological plasticity, long generation times, and slow rates of mitochondrial DNA evolution. Among Caribbean representatives of the genus Porites are three named species ( $P$. divaricata, $P$. furcata, and $P$. porites) with branching colony morphologies whose validity as genetically isolated species has been debated. We present sequence data from the mitochondrial control region, nuclear ITS, and nine single-copy nuclear loci for the Caribbean Porites and a related eastern Pacific species. mtDNA sequences were nearly invariant among the three branching species and their crustose sister P. branneri,
\end{abstract}

Communicated by Biology Editor Dr. Ruth Gates

Electronic supplementary material The online version of this article (doi:10.1007/s00338-014-1179-5) contains supplementary material, which is available to authorized users.

C. Prada · M. B. DeBiasse · M. E. Hellberg ( $₫)$

Department of Biological Sciences, Louisiana State University,

Baton Rouge, LA 70803, USA

e-mail: mhellbe@1su.edu

J. E. Neigel · B. Yednock · J. L. Stake

Department of Biology, University of Louisiana at Lafayette,

PO Box 42451, Lafayette, LA 70504, USA

Present Address:

J. L. Stake

Department of Biology, Rivier University, 420 So. Main St., Nashua NH 03062, USA

\section{Z. H. Forsman}

Hawaii Institute of Marine Biology, PO Box 1346, Kaneohe, HI 96744, USA

I. B. Baums

Department of Biology, Pennsylvania State University, 208

Mueller Laboratory, University Park, PA 16802, USA and ITS sequences from these four were intermingled. An information theoretic analysis provided no support for upholding the three named Caribbean branching species. Both a clustering analysis and an analysis of molecular variance showed that sequence variation from the three branching forms is partitioned more by geography than by taxonomy. Multi-locus coalescent phylogenetic analysis provided a calibrated estimate for the nuclear DNA substitution rate $\left(0.14 \% \mathrm{Ma}^{-1}\right)$ close to that for other corals. Because no generalities have emerged from genetic investigations of the validity of morphologically defined coral species, the use of single-copy nuclear data is likely to be important in testing problematic species designations.

Keywords Information theory - mtDNA - rRNA · Nuclear genes $\cdot$ Substitution rate

\section{Introduction}

Colony morphology is highly plastic in many corals (Todd 2008), and this plasticity has been blamed for the oftenconfused state of coral taxonomy revealed by genetic studies (Fukami et al. 2004b). Multiple named morphospecies have in some cases turned out to be a single interbreeding species (Eytan et al. 2009; Stefani et al. 2011; Pinzón et al. 2013). Conversely, what had been thought to be multiple growth forms within a species can turn out to be a complex of species (Fukami et al. 2004a). Moreover, even morphologically identical forms can be genetically isolated at the level of populations (Baums et al. 2005) or cryptic species (Forsman et al. 2009), with these isolated units exhibiting different reproductive modes (Baums et al. 2006) and ecological interactions (Boulay et al. 2014). 
Genetic differences provide the basis for delineating species when morphology cannot, but again corals pose more challenges than most other animals. Slow rates of nucleotide substitution in the mtDNA of corals (Hellberg 2006) yield few differences between closely related coral species. The ribosomal internal transcribed spacer (ITS) regions have provided a faster changing, if controversial (Vollmer and Palumbi 2004), nuclear alternative. While sometimes effective in distinguishing cryptic species (Forsman et al. 2009; Stefani et al. 2011), the high copy number of ITS fragments precludes their use in detecting population structure within species or detecting isolated species using emerging coalescent analyses.

Coalescent analyses are increasingly used to untangle mismatches between the histories of genes and species (Maddison 1997). These mismatches are especially likely to arise when effective population sizes $\left(N_{\mathrm{e}}\right)$ are large and divergence times are recent, conditions under which neutral genes will often fail to be reciprocally monophyletic or even paraphyletic between isolated groups (Neigel and Avise 1986). The effective population sizes of reef corals can be large, as evident from high allelic diversity and sequence divergence found in genetic surveys (Eytan et al. 2009; Nunes et al. 2009). Generation times are long (Potts et al. 1985), often on the order of decades and potentially far longer, as some very large old individuals may contribute disproportionately to reproductive output (Beiring and Lasker 2000).

New multi-locus coalescent analyses offer the prospect of delineating species and inferring their relationships even when no single locus is by itself diagnostic (Edwards 2009). When not just relationships, but even the number of species are in question, a combined coalescent and information theoretic approach (Carstens and Dewey 2010) can weigh the relative ability of alternative taxonomic groupings and relationships to explain the observed data in a coalescent framework. One drawback of this approach, however, is that the user must define each species a priori; failure to do so (such as for cryptic species) may confound results. At the opposite extreme, Bayesian clustering (Pritchard et al. 2000) allows the detection of isolated groups from multi-locus genotypes and can be carried out without any a priori grouping. These clustering algorithms work by forming groups that maximize Hardy-Weinberg equilibrium and minimize linkage disequilibrium (LD) within groups while maximizing LD among groups. Because LD forms and breaks down quickly, the resolution of clustering programs identifies units finer than those for which species designation is appropriate. At a minimum, however, genetically isolated species should (if real) fall out as clusters before other clusters do (e.g., geographically isolated populations).

We applied multi-locus coalescent and Bayesian clustering analyses to sequence data from eleven genetic markers to test species designations for Caribbean species of the genus Porites, an important reef builder that can dominate local habitats (Glynn 1973; Aronson et al. 2004). We also use these genetic data to infer relationships among confirmed taxa and to estimate the species' time of divergence and rates of evolution for our genetic markers.

Six species of Porites have been described in the Caribbean based on morphological criteria. Three of these are quite easily distinguished from the others. Porites astreoides is distantly related to the other species, belonging to a lineage that dominates in the more diverse western and central Pacific (Budd et al. 1994; Forsman et al. 2009). Its range extends south beyond the Caribbean into tropical Brazil. Porites branneri was originally described from Brazil (Laborel 1969), although corals matching its morphology occur in the Caribbean and have been referred to by that name (Humann 1993). While it has sometimes been confused with $P$. astreoides (Bouchon and Laborel 1988), the two are genetically distinct in the Caribbean (Weil 1992). P. colonensis forms colonies of flattened and fused branches and is endemic to Panama (Zlatarski 1990).

The taxonomic status of the three remaining branching species, $P$. porites, $P$. furcata, and $P$. divaricata, has been contentious. Some studies have found near-continuous morphological variation among these three Caribbean branching species (Brakel 1977). Others report morphological breaks consistent with species designations (Weil 1992; Jameson 1997), firmly suggesting that the three are different species (Jameson and Cairns 2012). These three nominal species tend to occupy different microhabitats (Bouchon and Laborel 1988; Jameson 1997), but these differences are not absolute. All three possess Caribbean-wide geographic ranges and brood larvae that may disperse for up to $30 \mathrm{~d}$ (Schlöder and Guzman 2008). Genetic studies have yet to resolve the issue, although those to date lean toward recognizing the three branching species as distinct. Weil (1992) used genetic distances based on 11 polymorphic allozymes to infer relationships among Caribbean Porites, but allele frequencies and support values for the monophyly of taxa were not presented. Forsman et al. (2009) included samples of $P$. divaricata and $P$. furcata in their ITS-based phylogeny of the genus, finding sequences from two Belizean individuals of the former to be distinct from those from one Panamanian individual of the latter.

Here, we test whether the three nominal Caribbean branching species constitute genetically isolated species against the alternative that they constitute a single gene pool. We also use the data to infer relationships among the Caribbean Porites and a close eastern Pacific relative, and to calibrate a molecular clock using paleontological data.

\section{Methods}

Collection and genotyping of samples

We collected genetic data from 50 individuals of the six Caribbean species of Porites plus an eastern Pacific 
Table 1 Porites samples analyzed in this study, with locality information for new samples

\begin{tabular}{|c|c|c|c|}
\hline Species & Location & $N$ & Collector \\
\hline \multirow[t]{3}{*}{ P. astreoides } & Panama & 2 & C. Guevara \\
\hline & Belize & 1 & G. Wellington \\
\hline & Puerto Rico ${ }^{a}$ & 2 & Prada \\
\hline P. colonensis & Panama & 2 & J. Mate \& H. Guzman \\
\hline \multirow[t]{2}{*}{ P. panamensis } & Panama & 2 & J. Mate \& H. Guzman \\
\hline & Baja California & 2 & B. Victor \\
\hline P. branneri & $\mathrm{USVI}^{\mathrm{b}}$ & 2 & Stake \\
\hline$P$. porites & Puerto Rico $^{\mathrm{a}}$ & 6 & Prada \\
\hline \multirow[t]{3}{*}{ P. divaricata } & USVI $^{\mathrm{b}}$ & 3 & Stake \\
\hline & Belize & 3 & G. Wellington \\
\hline & Panama $^{c}$ & 2 & DeBiasse \\
\hline \multirow[t]{5}{*}{$P$. furcata } & Puerto Rico ${ }^{\mathrm{d}}$ & 3 & Prada \\
\hline & Dominican Republic ${ }^{\mathrm{e}}$ & 3 & D. Ruiz \\
\hline & $\mathrm{USVI}^{\mathrm{f}}$ & 2 & Stake \\
\hline & Panama $^{c}$ & 12 & C. Guevara, DeBiasse \\
\hline & Curaçao $^{\mathrm{g}}$ & 3 & D. Ruiz \\
\hline
\end{tabular}

a $17^{\circ} 56.093 \mathrm{~N}, 67^{\circ} 02.931 \mathrm{~W}$ (Media Luna Reef)

b $18^{\circ} 30.183 \mathrm{~N}, 64^{\circ} 21.467 \mathrm{~W}$ (Cass Cay)

c $9^{\circ} 06.401 \mathrm{~N}, 82^{\circ} 15.622 \mathrm{~W}$ (Bocas del Toro)

d $17^{\circ} 57.562 \mathrm{~N}, 67^{\circ} 02.280 \mathrm{~W}$ (Las Terrazas)

e $19^{\circ} 19.602 \mathrm{~N}, 69^{\circ} 33.045 \mathrm{~W}$ (Playa Mujeres)

f $18^{\circ} 20.747 \mathrm{~N}, 64^{\circ} 59.142 \mathrm{~W}$ (Black Point)

g $12^{\circ} 11.604 \mathrm{~N}, 68^{\circ} 04.830 \mathrm{~W}$ (Port Marie)

member of the same clade (Table 1). All corals were legally collected under permits issued by the countries in which collections were made. We focused on the three branching Caribbean species, for which we collected 37 individuals among six localities. Thirteen individuals had previously been analyzed for ITS and mtCR sequences by Forsman et al. (2009). In addition to new sequence data from single-copy nuclear markers for these 13 individuals, we also added complete multi-locus data sets from 37 new samples from Panama, Puerto Rico, the Dominican Republic, and the US Virgin Islands (Table 1). Individual colonies were identified using standard keys (Humann 1993) with special reference to the diameter and spacing of branches and to microhabitat, in accordance with the species discriminations made by Jameson (1997) and Jameson and Cairns (2012).

Individuals of $P$. furcata were collected in sympatry with the two other branching species at three locations (with $P$. porites from Puerto Rico and with $P$. divaricata from Panama and the US Virgin Islands). At each of these three locations, collections were made from different habitats where one of the three forms is expected to dominate to assure sampling of clear exemplars of each species: $P$. porites from the fore reef at $15 \mathrm{~m}, P$. furcata from high energy reef crests about $1 \mathrm{~m}$ deep, and $P$. divaricata from shallow protected back reefs. While a balanced design sampling all three nominal branching species from the same locales would have been preferable (the samples we used were collected opportunistically as other projects permitted), our sampling allows an examination of the power of current taxonomy to explain genetic variation within and among branching Caribbean Porites.

$P$. panamenis is a broadly ranging Eastern Pacific species. A morphologically similar endemic to the Gulf of California, P. sverdrupi, has been described (López-Pérez et al. 2003), and Forsman et al. (2009) included samples identified as such. However, Forsman et al.'s samples were from Punta Chivato, a site where previous work has not reported P. sverdrupi (Paz-García et al. 2008). As morphological vouchers for those samples are unavailable, we refer to them as $P$. panamensis herein.

We obtained genotypes for all individuals for five single-copy nuclear markers (two introns, two open reading frames, and one anonymous region, totaling $\geq 2,103 \mathrm{bp}$ per individual), a multi-copy nuclear gene (597-660 bp of the ITS), and a mitochondrial marker (274 bp of the control region, CR). An additional four anonymous nuclear markers (Pbr27, Pbr28, Pbr44, and Pbr74) totaling 1,445+ bp (see Electronic Supplementary Materials, ESM, Table S1) were used for the three branching Caribbean species. The ITS and CR regions were sequenced to facilitate comparisons to earlier genetic work on Caribbean Porites by Forsman et al. (2009). We chose to otherwise focus on single-copy nuclear markers because, unlike ITS, they can be employed in coalescent analyses that account for lineage sorting among recently diverged taxa. In addition, substitution rates are five to eight times faster in the nuclear genome of corals than for their mtDNA and comparable to those seen in other animals (Eytan et al. 2009).

ITS and CR sequences were amplified as in Forsman et al. (2009). Intronic sequence within ATPase $\beta$ was amplified using primers redesigned from Concepcion et al. (2008). Anonymous marker (An1) came from screening a $P$. compressa genomic library (Stake 2007). Four more anonymous markers resulted from a $P$. branneri genomic library, although these did not amplify consistently outside of $P$. branneri and the three branching Caribbean species. Three additional markers came from cDNA sequences posted by M. Matz (http://www.bio.utexas.edu/research/ matz_lab/matzlab/Data.html): two (MM32 and MM100) for coding regions to putative yolk proteins from $P$. compress $a$ and another flanking an intron for a homolog to the urchin Receptor for Egg Jelly (REJ) from P. astreoides.

DNA was extracted using the DNeasy Tissue Extraction Kit (Qiagen). PCR amplifications were performed in a BioRad T100 with cycling conditions as described in Eytan et al. (2009) and annealing temperatures of 50 or $52{ }^{\circ} \mathrm{C}$. 
Amplicons (uncleaned) were sequenced in both directions on an ABI 3130xl using the amplification primers. Ambiguous heterozygotes were cloned to resolve both alleles. All sampled colonies had unique multi-locus genotypes, and thus did not belong to the same genet. We used SITES v1.1 (Hey and Wakeley 1997) to calculate population genetic summary statistics after excluding indels.

To insure that the full lengths of our nuclear markers had a common history, we tested for recombination using TOPALI v2 with the difference of sums of squares (DSS) method, the model of evolution suggested the Perl script MrAIC 1.4.4 (Nylander 2004), and a sliding window of $100 \mathrm{bp}$ with a $10 \mathrm{bp}$ step size (Milne et al. 2004).

\section{Gene trees}

The phylogenetic program PhyML v3.0 (Guindon et al. 2010) was used to search for maximum likelihood trees with 1,000 replicates for bootstraps, and with MrAIC to select models of sequence evolution by the AICc criterion. Trees here and elsewhere were rooted with sequences from P. astreoides, which both morphological (Budd et al. 1994) and genetic (Forsman et al. 2009) studies support as belonging to a separate lineage from the rest of the Caribbean species of Porites.

\section{Delineating taxa}

We used information theory, as proposed initially by Anderson (2008) and subsequently modified for testing alternative models of phylogeny by Carstens and Dewey (2010), to see whether the delineation of all Caribbean branching species as phylogenetically distinct was warranted. STEM v2.0 (Species Tree Estimation using Maximum likelihood) is a maximum likelihood approach that uses the coalescent to reconstruct species trees given resolved gene trees for a sample of marker loci (Kubatko et al. 2009). We used STEM to compute the likelihood for five alternative species trees. Each tree, which we consider alternative hypotheses, differed in the degree to which they combined species or the topology of species (see left column of Table 3). The PhyML topologies for the five singlecopy nuclear genes were used as gene trees for the STEM analysis. The two most distant outgroup taxa $(P$. astreoides and $P$. colonensis) were omitted from this analysis to concentrate on differences among the crown taxa.

We used likelihood scores calculated in STEM for each species topology and ranked the trees using information theory (Anderson 2008) to evaluate whether a splitting between the three Caribbean branching species were justifiable. In brief, we calculated the likelihood score for each topology, which represents an alternative evolutionary model. We then calculated the AIC (Akaike Information Criterion) for each topology, considering the likelihood scores and the number of parameters. Each tip (species) represents an additional parameter, so that trees with more tips have more parameters and are expected to better explain the data. We ranked models by AIC scores, the lowest score being the best model. Delta values $(\Delta i)$ were calculated as the difference between the best model and each of the alternative models. We then calculated model probabilities following the Akaike approximation, which uses the $\Delta i$ scores. We summed the relative likelihoods for all models and calculated the ratio of each model against this grand sum to obtain the model probability $\left(w_{i}\right)$. The evidence ratio $E$ is the ratio of two models' $w_{i}$ values; $E_{\min / i}$ is the special case for a particular model's $w_{i}$ compared to that $\left(w_{\min }\right)$ for the best model. Evidence ratios can be used to evaluate the relative efficacy of the models with different numbers of parameters in explaining the data (Anderson 2008). Carstens and Dewey (2010) developed this approach using a data set (34 individuals, six named species, six nuclear loci) similar to that employed here (43 individuals, five named species, ten nuclear loci).

To further inspect for a signal of support at nodes for named species, we also evaluated species delimitation using a Bayesian approach (BPP, Yang and Rannala 2010) following earlier studies (Leaché and Fujita 2010). We ran a rjMCMC for 500,000 generations with an internal sampling of five and a burnin period of 50,000. We ran the program at least three times for each parameter combination using different starting seeds to assess consistency. During the rjMCMC, we used a fine tuning parameter of five. Prior probabilities for each delimitation model were the same.

\section{Testing for geographic differentiation}

Because the delineation of the Caribbean branching species received no support (see Results), genetic data from the three branching species were pooled and patterns of population structure among them were inferred using Bayesian clustering. In STRUCTURE v2.3.4 (Pritchard et al. 2000), we varied $k$ from 1 to 9 and used the admixture model with a burnin of 100,000 steps followed by 20 million iterations and ten replicates per run. No information about the geographic source of individuals was used. We estimated the most likely number of populations $(k)$ in two ways: using the Evanno et al. (2005) method implemented by STRUCTURE HARVESTER v0.6.93 (Earl and vonHoldt 2011) and using STRUCTURAMA v2.0 (Huelsenbeck et al. 2011). In STRUCTURAMA, we used a fixed alpha value of 0.1 and an admixture model. We used a small alpha because we suspected that $k$ was small $(<10)$. The Evanno method suggested $k=3$, while in STRUCTURAMA, the number of populations with the 
highest probability fluctuated between two and four among different runs. We thus used STRUCTURE to infer clusters using these three $k$ values.

While the sample sizes used here $(N=37)$ are modest for such clustering analyses, simulations (Rittmeyer and Austin 2012) show they still have high power to detect cryptic species even with smaller samples sizes and fewer loci than employed here.

The relative proportion of genetic variation accounted for by the three nominal taxa and by geography (the three geographic lineages revealed by the STRUCTURE analysis) was analyzed using an analysis of molecular variance (AMOVA) as implemented in GenoDive v2.0b22 (Meirmans and Van Tienderen 2004). We used two approaches in GenoDive. The first is based on the observed within-population diversity as inferred from our empirical data. To avoid the effects of high within-population diversity on estimating between-population differences, we also calculated a standardized $F$-statistic proposed by Hedrick (2005). Standard errors for $F$-statistics were obtained by jackknifing over loci using 999 permutations.

Resolving species trees and inferring rates of substitution within Porites

To accommodate discordance among gene trees due to incomplete lineage sorting, we used the coalescent-based approach implemented in *BEAST v 1.7.3 (Heled and Drummond 2010), the only multi-locus coalescent analysis that allows dating of nodes directly on the species tree (McCormack et al. 2011). Dates were calibrated using priors for the split between two major lineages within Porites (Budd et al. 1994): one in which colonies are large and mounding (represented here by $P$. astreoides), the other containing species whose colonies are smaller and more branching. These lineages split no less than $28 \mathrm{Ma}$, but must be younger than the genus (40 Ma; Budd 2000). We used these fossilderived dates to calibrate our phylogeny.

We estimated split times in four ways. First, we used a minimum constraint by defining a uniform prior distribution with a lower bound of $28 \mathrm{Ma}$ and an upper bound of $80 \mathrm{Ma}$ (twice the maximum split). Second, we used a maximum constraint by defining a uniform prior distribution with an upper bound of $40 \mathrm{Ma}$ and a lower bound of zero. Third, we used a lognormal distribution with a mean value of $34 \mathrm{Ma}$, a hard minimum bound of $28 \mathrm{Ma}$, and a hard maximum of 40 Ma. Fourth, we used rates (0.09-0.11\% per million years) previously inferred for nuclear genes from acroporids ( $\mathrm{Pa}-$ lumbi et al. 2011; Voolstra et al. 2011). All four approaches provided similar divergence time estimates and were well within the 95 HPDs. We present the lognormal distribution results, as these are considered the most appropriate when using fossils for calibration (Ho and Phillips 2009).
Table 2 Nucleotide, allelic, and genotypic variation observed at 10 marker loci in the three nominal species of branching Caribbean Porites

\begin{tabular}{|c|c|c|c|c|c|c|c|}
\hline Locus & $S$ & $\theta$ & $\pi$ & $\begin{array}{l}\# \\
\text { Alleles }\end{array}$ & $\begin{array}{l}\text { Eff. \# } \\
\text { alleles }\end{array}$ & $H_{\mathrm{S}}$ & $H_{\mathrm{T}}$ \\
\hline $\mathrm{mtCR}$ & 3 & 2.59 & 0.56 & 3 & 1.09 & 0.12 & 0.11 \\
\hline An1 & 17 & 11.41 & 13.12 & 10 & 1.97 & 0.62 & 0.84 \\
\hline ATPase & 7 & 2.88 & 0.84 & 8 & 1.29 & 0.28 & 0.28 \\
\hline MM32 & 2 & 0.95 & 0.42 & 3 & 1.12 & 0.13 & 0.18 \\
\hline MM100 & 3 & 3.95 & 1.71 & 4 & 1.22 & 0.23 & 0.26 \\
\hline REJ & 12 & 4.00 & 2.80 & 10 & 1.49 & 0.44 & 0.67 \\
\hline Pbr27 & 7 & 6.26 & 9.69 & 8 & 2.33 & 0.66 & 0.80 \\
\hline Pbr 28 & 11 & 4.74 & 7.22 & 9 & 1.32 & 0.29 & 0.70 \\
\hline Pbr44 & 37 & 16.43 & 16.30 & 30 & 2.46 & 0.71 & 0.92 \\
\hline Pbr74 & 3 & 2.04 & 1.84 & 4 & 1.85 & 0.54 & 0.54 \\
\hline Mean & 10.20 & 5.53 & 5.45 & 8.90 & 1.61 & 0.40 & 0.53 \\
\hline SD & 10.60 & 4.81 & 5.79 & 7.94 & 0.51 & 0.22 & 0.30 \\
\hline
\end{tabular}

Means and standard errors (SE) are for the nine nuclear loci only. Results based on 35 individuals from $P$. divaricata, $P$. furcata, and $P$. porites and include both alleles from nuclear markers

Both $\theta$ and $\pi$ are per bp and $(\times 1,000)$

$S=\#$ segregating sites, $H_{\mathrm{S}}=$ heterozygosity within populations, $H_{\mathrm{T}}=$ total heterozygosity, eff. \# alleles = effective number of alleles

We assumed a Yule model and strict clock for all genes except for mtCR, for which we used an uncorrelated lognormal relaxed clock. We chose these conditions based on preliminary analyses using the ucld.stdev parameter in *BEAST, which will be close to 0 if the data are clock-like and significantly greater than 1 if there is substantial rate heterogeneity among lineages (Drummond and Rambaut 2007). Chain lengths were $5 \times 10^{8}$ and sampled every $10^{4}$ steps. We used TREE ANNOTATOR to generate the consensus tree and estimate the posterior probabilities of each node from two independent runs (Rambaut and Drummond 2007) after discarding $10 \%$ as burn in. We assessed convergence by inspecting ESS values that were $>200$ in TRACER v1.5 (Rambaut and Drummond 2007). We repeated this procedure twice.

Generation times were estimated at $11.5 \mathrm{yr}$ for $P$. astreoides based on the size at which colonies become reproductive (Soong 1993) and the time required to reach this size based on growth rates (Chornesky and Peters 1987).

\section{Results}

\section{Gene trees}

Gene regions were variable within species (Table 2), at least within the three Caribbean branching species, where heterozygosity was high $\left(H_{\mathrm{T}}=0.56, \mathrm{SE}=0.082\right)$. The 


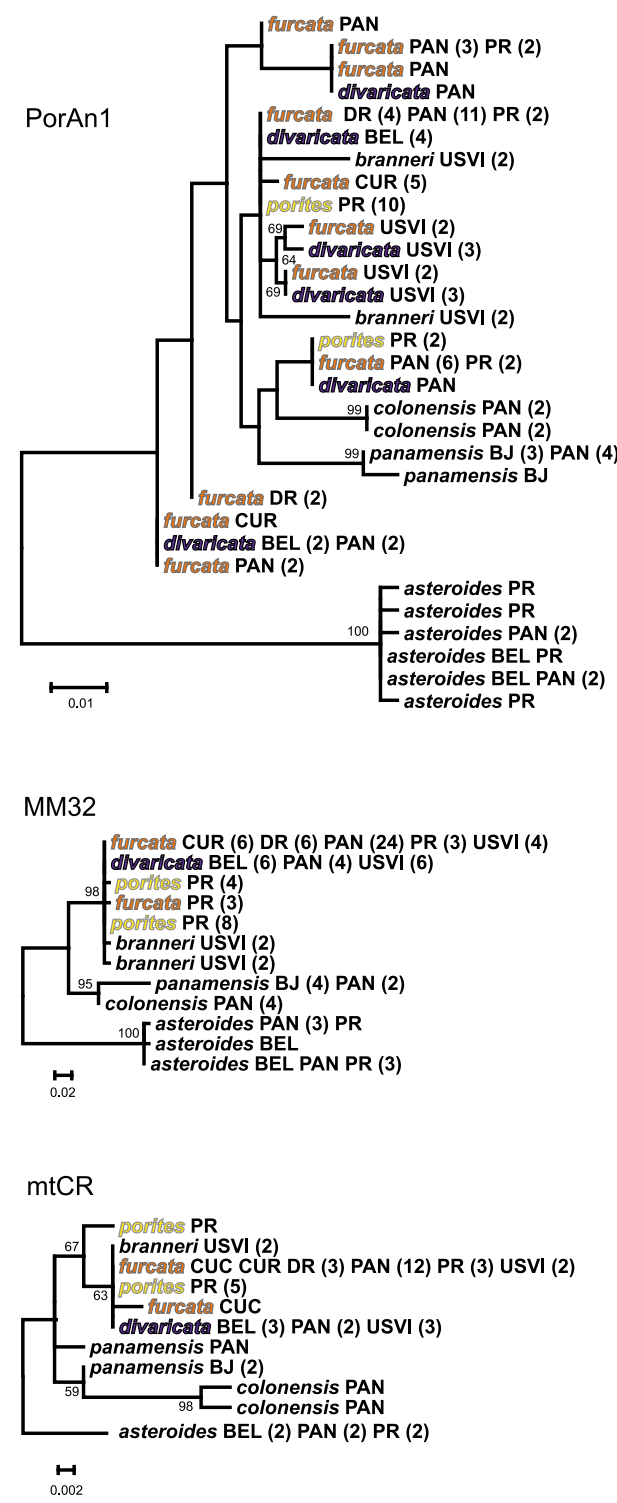

Fig. 1 Maximum likelihood gene trees for five single-copy nuclear genes and the mitochondrial control region (mtCR) from Porites species. Labels designate the nominal species followed by the sampling locality (see Table 1) and the number of alleles (in

data were complete for all loci for these three taxa, except for the REJ intron for one $P$. furcata individual from Puerto Rico and one $P$. divaricata individual from Belize. Tests carried out in TOPALI did not reveal intra-locus recombination.

Single gene trees (Fig. 1; ESM Fig. S1) consistently distinguished $P$. asteroides, $P$. panamensis, and $P$. colonensis, although the phylogenetic placement of the latter two varied among different loci. Porites panamensis was best supported as sister to P. colonensis for MM32 and MM100, and as the sister to a group including $P$. branneri and the three branching species for ATPase $\beta$, REJ, and ITS. There

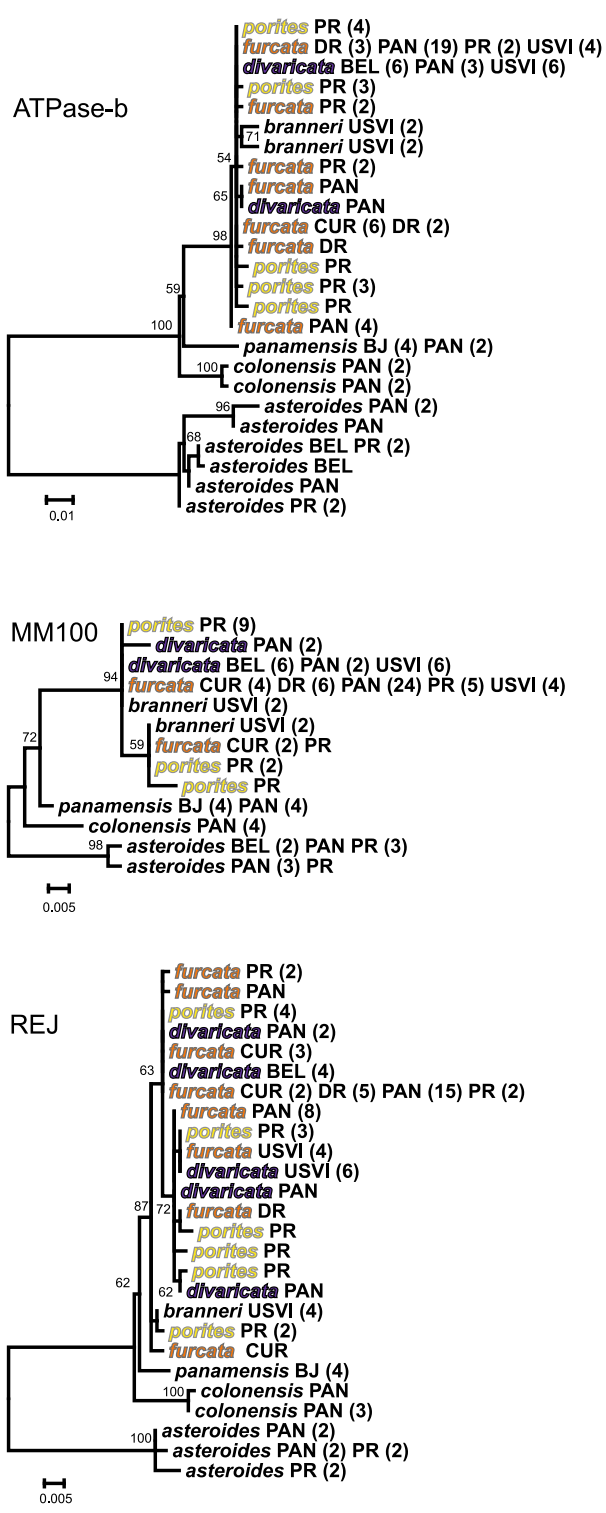

parentheses). Bootstrap values $>50 \%$ are shown above branches. Individuals of the same species that appear separately on zero-length branches differ by indels

were trees with high bootstrap support in both opposing cases: $97 \%$ for the MM32 tree pairing P. panamensis and P. colonensis, and $92 \%$ for the ITS tree placing P. panamensis as sister to the Caribbean clade of four species.

Sequences from $P$. branneri were monophyletic for ATPase $\beta$ and unique for PorAn1, MM32, and REJ, but shared with those of the three Caribbean branching species at MM100 and mtCR (Fig. 1). Alleles were commonly shared among the three nominal branching species: 37 of 39 of the three branching species along with $P$. branneri were fixed for the same mitochondrial CR haplotype. ITS sequences (ESM Fig. S1) were intermingled for the three 
Table 3 Summary of information theoretic assessment of species limits within the genus Porites in the Caribbean

\begin{tabular}{lllllll}
\hline & \#taxa & $\log L$ & AICc & L(modelldata) & wi & Ratio \\
\hline pan, br_por_div_fur & 2 & $-37,267.00052$ & $74,538.0010$ & 1 & 1 \\
pan, br, por_div_fur & 3 & $-39,586.95541$ & $79,179.9108$ & $<10^{-217}$ & $<10^{-217}$ \\
pan, br, por, div_fur & 4 & $-39,586.37319$ & $79,180.7464$ & $<10^{-217}$ & $<10^{-217}$ \\
pan, br, fur, por_div & 4 & $-39,919.92458$ & $79,847.8492$ & $<10^{-217}$ & $<10^{-217}$ \\
pan, br, div, por_fur & 4 & $-39,920.30228$ & $79,848.6046$ & $<10^{-217}$ & $<10^{217}$ \\
pan, br, div, por, fur & 5 & $-39,920.19582$ & $79,850.3916$ & $<10^{-217}$ & $<10^{217}$ \\
pan, br, por_div_fur & 3 & $-39,586.95541$ & $79,179.9108$ & 1 & $>10^{-217}$ \\
pan, br, por, div_fur & 4 & $-39,586.37319$ & $79,180.7464$ & 0.658507 & $>10^{217}$ \\
pan, br, fur, por_div & 4 & $-39,919.92458$ & $79,847.8492$ & $<10^{-145}$ & 0.397048 \\
pan, br, div, por_fur & 4 & $-39,920.30228$ & $79,848.6046$ & $<10^{-145}$ & $<10^{-145}$ \\
pan, br, div, por, fur & 5 & $-39,920.19582$ & $79,850.3916$ & $<10^{-145}$ & $<1.518586$ \\
\hline
\end{tabular}

pan $=P$. panamensis, br $=P$. branneri, por $=P$. porites, $\operatorname{div}=P$. divaricata, fur $=P$. furcata

Nominal species separated by “,” were treated as separate, those joined by "_, were combined

$-\log \mathrm{L}=\log$ likelihood of the species tree

$\mathrm{AICc}=$ corrected Akaike information criterion

$L($ modelldata $)=$ relative likelihood of model given the data

$w \mathrm{i}=$ model probabilities

Ratio $=$ evidence for compared to best model

branching species and $P$. branneri, but were monophyletic for the three other species.

Species delineation

We used STEM to compare models in which all three branching Caribbean species were grouped together to those in which the branching species were all distinct or combined with each other or with $P$. branneri (Table 3 ). The tree with the greatest likelihood was that in which $P$. branneri and the three branching Caribbean species were collapsed into one taxon. The next most likely topology separated $P$. branneri from the three branching species. Together, these two topologies accounted for $>99 \%$ of total model probabilities. Two models in which all named species were fully resolved (but differed topologically) accounted for essentially none of the total model probability. Overall, the STEM method of species delineation provided no support for separation of the three branching Caribbean Porites or even for the distinctiveness of P. branneri.

To further explore the unexpected failure of $P$. branneri to separate from the three branching species, we used BPP to evaluate the support for a separate node leading to $P$. branneri when the three branching species were set as monophyletic. Replicate runs yielded supports of 1.00, 0.55, and 1.00, suggesting some support for maintaining $P$. branneri as a separate species. Given our limited sampling of this species (just two individuals), we excluded it from ensuing analyses of variation within the three branching species.

Geographic differentiation

After failing to find evidence of phylogenetic differentiation among $P$. porites, $P$. divaricata, and $P$. furcata, we used STRUCTURE to try to identify clusters of genetically similar individuals within the 37 individuals pooled from these three branching species. Likelihood scores indicated $K=3$ as the most likely number of clusters. These clusters do not reflect the three nominal species, however, nor do they have a strong geographic component (Fig. 2). All individuals from the Virgin Islands fell into a common cluster, but these nominal $P$. divaricata did not group with other highly branched forms from other locations. Individuals from Belize and Curaçao clustered similarly, as did those from the Dominican Republic and Puerto Rico, despite mixed species identifications. Individuals were more mixed among clusters in Panama than elsewhere, but these assignments showed no relation to nominal species designations, even though species identifications were made along a clear habitat and colony morphology gradient (Fig. 2).

AMOVA suggests the role of geography is stronger than that of nominal species designation in partitioning genetic variation among the individuals sampled from the three branching Caribbean forms (Table 4). For uncorrected values, geographic location accounted for $16 \%$ of the total 


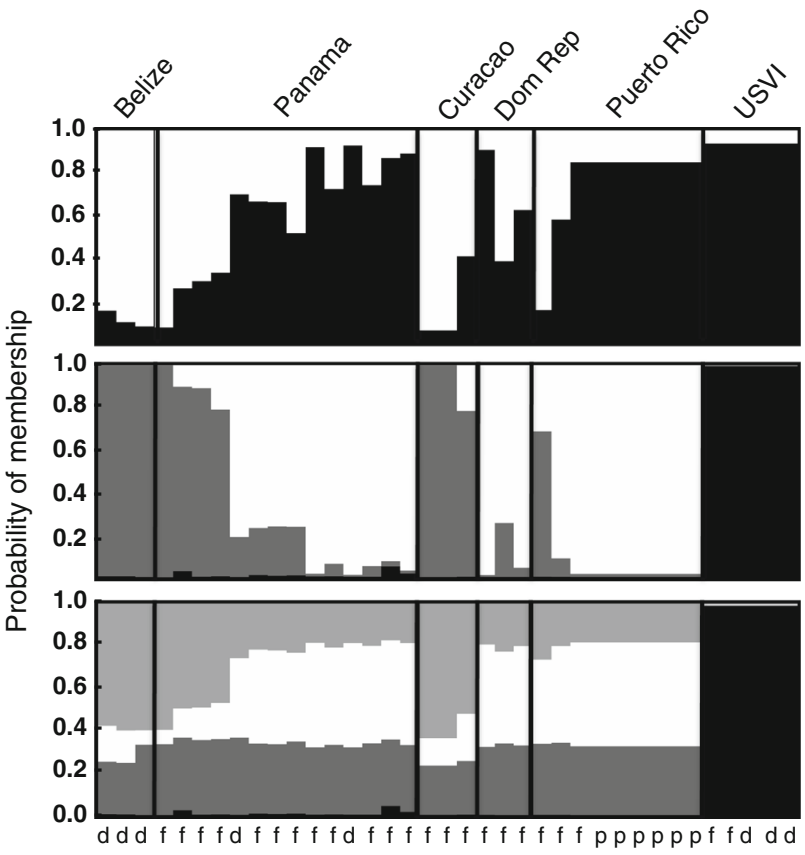

Fig. 2 Results of the STRUCTURE analysis for $k=2$ (top), 3 and 4 (bottom). Each vertical bar represents an individual, with the proportion of its genome originating from each of the three clusters indicated by different shades. The geographical origin of individuals is indicated at top, their morpho-species identification along the bottom. Dom Rep $=$ Dominican Republic, USVI $=$ US Virgin Islands; $\mathrm{d}=$ Porites divaricata, $\mathrm{f}=P$. furcata, $\mathrm{p}=P$. porites

Table 4 Analysis of molecular variance among samples of the three nominal branching species of Caribbean Porites attributable to taxonomic designation and geography based on 10 loci

\begin{tabular}{|c|c|c|c|c|c|}
\hline Source of variation & $d f$ & $\begin{array}{l}\% \\
\text { variation }\end{array}$ & $F$ value & SD & $P$ value \\
\hline \multicolumn{6}{|l|}{ Corrected } \\
\hline Among locations & 5 & 53.7 & 0.537 & 0.08 & 0.001 \\
\hline $\begin{array}{l}\text { Among "taxa" within } \\
\text { locations }\end{array}$ & 3 & 2.4 & 0.053 & 0.038 & 0.036 \\
\hline $\begin{array}{l}\text { Among individuals } \\
\text { within taxa }\end{array}$ & 28 & 10.7 & 0.243 & 0.082 & $<0.001$ \\
\hline Within individuals & 37 & 33.2 & 0.668 & 0.076 & - \\
\hline \multicolumn{6}{|l|}{ Uncorrected } \\
\hline Among locations & 5 & 16 & 0.16 & 0.053 & 0.01 \\
\hline $\begin{array}{l}\text { Among "taxa" within } \\
\text { locations }\end{array}$ & 3 & 4.5 & 0.054 & 0.038 & 0.038 \\
\hline $\begin{array}{l}\text { Among individuals } \\
\text { within taxa }\end{array}$ & 28 & 18.5 & 0.232 & 0.079 & $<0.001$ \\
\hline Within individuals & 37 & 61 & 0.39 & 0.079 & - \\
\hline
\end{tabular}

$\mathrm{SD}=$ standard deviation, $\mathrm{df}=$ degrees of freedom

genetic variation while taxonomic designation explained just $4.5 \%$. Correcting for high levels of within-population variation, differences are more extreme: geographic

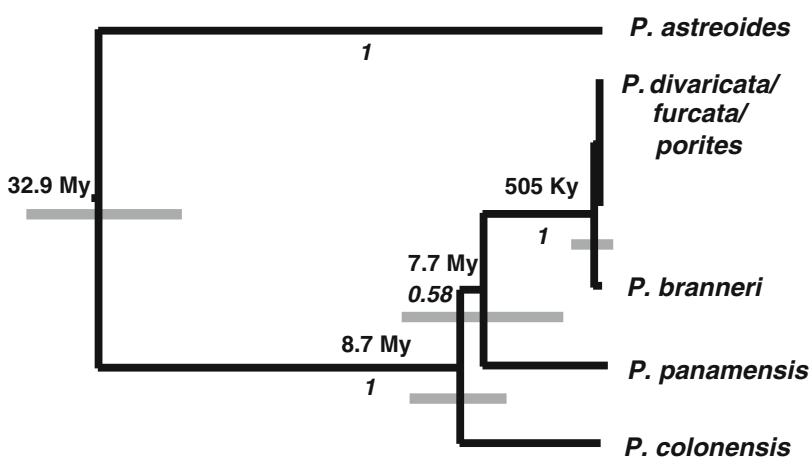

Fig. 3 Species tree for the six named Caribbean Porites species and a Pacific species based on *BEAST analysis of six loci. Clade support (italics) and best estimate of species divergence times (bold) indicated, with dates calibrated by a prior of 28-40 My set for the divergence of $P$. astreoides and the others (asterisk)

Table 5 Estimated rates of nucleotide substitution (rate in \% per $\mathrm{Ma})$ for one mitochondrial and five nuclear markers in the genus Porites

\begin{tabular}{llll}
\hline Marker & Genome & Rate & nDNA/mtDNA \\
\hline CR & mtDNA & 0.079 & - \\
An1 & Nuclear & 0.172 & 2.18 \\
ATPase $\beta$ & Nuclear & 0.206 & 2.61 \\
MM32 & Nuclear & 0.124 & 1.57 \\
MM100 & Nuclear & 0.076 & 0.96 \\
REJ & Nuclear & 0.111 & 1.41 \\
Nuclear DNA & Mean & 0.138 & 1.75 \\
& SD & 0.051 & 0.65 \\
\hline
\end{tabular}

location accounted for $53.7 \%$ of the total genetic variation, while taxonomic designation explained just $2.4 \%$.

Species topology, divergence times, and substitution rates in Porites

Relationships inferred using the multi-locus coalescent approach of *BEAST (Fig. 3) were generally similar to those inferred for individual genes. Porites branneri was placed as sister to the three collapsed Caribbean branching species with a common ancestor about $0.5 \mathrm{Ma}$. Support was strongest for a tree placing the eastern Pacific $P$. panamensis as the sister to a clade consisting of $P$. branneri and the three undifferentiated branching species, but topological uncertainty in this part of the tree was reflected by the overlap of confidence intervals for divergences times at this node and that uniting these crown taxa with $P$. colonenesis.

Along with estimates of divergence time, *BEAST also provided estimates of nucleotide substitution rates 
(Table 5). The two slowest markers (CR and MM100) were also the least heterozygous (Table 2). Substitution rates for nuclear sequences ranged from the same as those for the mtDNA to about two and a half times faster with a mean $1.75 \times$ faster.

\section{Discussion}

Genetic analysis did not support the distinctiveness of three contested Caribbean branching species: $P$. divaricata, $P$. furcata, and $P$. porites. An information theoretic analysis concluded that a phylogeny that lumped these three, either together or with their sister species $P$. branneri, was thousands of times more likely than a tree with even just two genetically isolated species among the three nominal ones. The hypothesis that there are three distinct Caribbean branching taxa was not supported by our results (Table 3). Instead, a signal for geographic subdivision among pooled samples of the three species was somewhat evident, primarily in an AMOVA that showed some variation partitioned among sampling locales and virtually none among named taxa (Table 4).

The finding that morphologically defined species of corals are not genetically distinct has precedent. Forsman et al. (2010), for example, show that several named species within Montipora, including one petitioned for listing under the Endangered Species Act, were not genetically distinguishable. Even some distinct coral morphospecies long evident in the fossil record have turned out not to be genetically distinct taxa (Budd et al. 2012). Consideration of these instances should not lead to the broad conclusion that morphological studies have over-estimated coral species diversity, however. To the contrary, in other instances, broadly distributed nominal species have turned out to be composed of deeply divergent lineages (Keshavmurthy et al. 2013) and supposed ecomorphs have turned out to be genetically isolated (Knowlton et al. 1992, Carlon and Budd 2002; Prada et al. 2008; Schmidt-Roach et al. 2013). More confusingly, sympatric and highly similar growth forms have been revealed by genetic data to be cryptic species (Boulay et al. 2014). This cannot be dismissed as the result of the biases of particular workers or differing predilections among taxa, as both the lumping of species with dissimilar morphologies and the splitting of cryptic species have come out of the same study of a single group (Fukami et al. 2004a; Eytan et al. 2009; Forsman et al. 2009; Pinzón et al. 2013). Nor does reproductive biology offer much insight: while many aforementioned taxa with cryptic species are broadcasters and the three branching Porites here all brood their larvae; their closely related eastern Pacific kin, the brooder $P$. panamensis, harbors genetically differentiated ecomorphs (Paz-García et al.
2008). These disparate results imply that the validation of coral species must proceed on a case-by-case basis.

Our study reveals the dangers of confounding species and location. Forsman et al. (2009) found monophyletic ITS sequences from three $P$. divaricata individuals from Belize nested within those from one $P$. furcata individual from Panama. With the samples added here, the four original individuals no longer fall out into reciprocally monophyletic lineages that correlate with taxonomic designations (ESM Fig. S1). ITS sequences from additional samples of $P$. divaricata from Panama and the Virgin Islands consistently fall with the most common copy from a sympatric $P$. furcata sample. Sampling in Forsman et al. (2009) was concentrated on Pacific species, and indeed they revealed a further benefit of geographic sampling: two species ( $P$. lobata and $P$. evermanni) clearly distinct both genetically and morphologically at their Hawaiian type locality had assumed a near-identical morphology in the eastern Pacific only resolved by genetic differences (see Boulay et al. 2014).

The taxonomic distinctness of closely related coral species can vary across their geographic ranges due to variable rates of hybridization (Fukami et al. 2004a). As in plants, hybridization can be common in corals, as demonstrated via no-choice crosses (Willis et al. 1997), choice crosses (Fogarty et al. 2012), and rates of introgression (Ladner and Palumbi 2012). Hybridization could explain why the crustose $P$. branneri could not be reliably distinguished from the three branching taxa; allopatric samples of $P$. branneri from its Brazilian type locality are needed to resolve this possibility as well as to clarify its taxonomy. The coral studies that most convincingly demonstrate hybridization include samples from at least one locale where the hybridizing species are genetically distinct; we see no such instance here.

Another possible explanation for the data might be that the three branching forms represent plastic responses in colony phenotype within a single species. Transplant experiments have repeatedly documented habitat-induced changes to colony morphology (Todd 2008) and the three branching Porites species examined here are often associated with distinct microhabitats (Bouchon and Laborel 1988). Indeed, habitat is the single non-overlapping character in the morphometric analysis of the three branching species in Belize by Jameson (1997). Our samples were taken from habitats where most colonies shared a single form or along habitat gradients where one form switched over to another. Deeper sampling across microhabitats at individual locations would have improved our study but, given the lack of any suggestive genetic signal for the three named species, a field experiment that transplanted clonal fragments among habitats might prove more conclusive.

Finally, the three branching morphotypes may be reproductively isolated entities largely homogenized by 
gene flow, with only a few regions of the genome, likely under habitat selection, maintaining their distinctions. Such islands of divergence have been described in a number of species, including (as here) where ecologically differentiated forms meet in sympatry (Stolting et al. 2013). Between forms of the mosquito Anopheles gambiae, for example, differentiation is concentrated on islands that together occupy $<0.1 \%$ of the genome (Turner et al. 2005), a region far too small to be captured by a limited genetic survey like ours. Strong selection mediated by immigrant inviability can promote and maintain differentiation between reef depths, even in the face of strong gene flow (Prada and Hellberg 2013). A genome wide study (Andrew and Reiseberg 2013) could reveal islands of divergence among the three ramose Porites, although a closer examination of spawning times (Levitan et al. 2011) and gametic compatibility might more thoroughly test the validity of these ecotypes.

Although the range of morphologies seen within coral species varies widely, the rates of substitution in nuclear DNA that we found were consistent with those seen in other corals. The mean rate of nucleotide substitution that we found $(0.14 \%$ per My, Table 5) is similar to recently calibrated rates for nuclear genes in Acropora (Palumbi et al. 2011; Voolstra et al. 2011), even though these three studies draw from genes having a range of functions and employ different events to calibrate their rates. Voolstra et al. (2011) compiled 2,604 orthologous pairs of cDNA sequences from the Caribbean A. palmata and the Indo-Pacific A. millepora, finding an average divergence of about $0.42 \%$ between them. The fossil record sets the divergence of this pair at about 40-50 Mya (Wallace 1999), giving an overall average substitution rate of $0.093 \%$ per Ma. Palumbi et al. (2011) used values in this range $(0.09-0.11 \%)$ to date the divergence of two Caribbean species (Acropora cervicornis and A. palmata) using two nuclear genes and arrived at estimates of the time of most recent common ancestor (3.0 Ma) consistent with the fossil dating of their divergence. Thus, when suitable independent calibrations are not available, a rate of substitution in the neighborhood of $0.09-0.14 \%$ per Ma appears appropriate for corals.

This value for the nuclear substitution rate is similar to that observed in other animals, bracketing the estimate for galliform birds (Ellegren 2007), falling within the range seen in mammals (Jackson et al. 2009), and toward the higher end of the range described in plants (Smith and Donoghue 2008). This similarity for nuclear substitution rate suggests that the slow rates of mtDNA evolution demonstrated in corals and some other basal eukaryotes (Hellberg 2006) is specific to this organelle, in line with efficient mtDNA-specific DNA repair.
Acknowledgments This work was supported by NSF Grants OCE0550270 to MEH and IBB, DEB-1311579 to CP and MEH, and OCE0315995 to JEN. All sequences have been deposited in GenBank (accession numbers: KJ951071-KJ951985). All alignments along with sequences for MM100 are available from Dryad (doi:10.5061/ dryad.986kd). We thank the respective national jurisdictions for issuing collecting permits. D. Ruiz and D. Beltrán helped during field collections. J. McCormack provided a hand-edited *BEAST dated file.

\section{References}

Anderson DR (2008) Model based inference in the life sciences. Springer, New York

Andrew RL, Reiseberg LH (2013) Divergence is focused on few genomic regions early in speciation: incipient speciation in sunflower ecotypes. Evolution 67:2468-2482

Aronson RB, MacIntyre IG, Wapnick CM, O’Neill MW (2004) Phase shifts, alternative states, and the unprecedented convergence of two reef systems. Ecology 85:1876-1891

Baums IB, Miller MW, Hellberg ME (2005) Regionally isolated populations of an imperiled Caribbean coral, Acropora palmata. Mol Ecol 14:1377-1390

Baums IB, Miller MW, Hellberg ME (2006) Geographic variation in clonal structure in a reef building Caribbean coral, Acropora palmata. Ecol Monogr 76:503-519

Beiring EA, Lasker HR (2000) Egg production by colonies of a gorgonian coral. Mar Ecol Prog Ser 196:169-177

Bouchon C, Laborel J (1988) The coral communities of the Grand Cul-de-Sac Marin of Guadalupe Island. Proc 6th Int Coral Reef Symp 3:333-338

Boulay JN, Hellberg ME, Cortés J, Baums IB (2014) Unrecognized coral species diversity masks differences in functional ecology. Proc R Soc B Biol Sci 281:20131580

Brakel WH (1977) Corallite variation in Porites and the species problem in corals. Proc 3rd Int Coral Reef Symp 1:457-462

Budd AF (2000) Diversity and extinction in the Cenozoic history of Caribbean corals. Coral Reefs 19:25-35

Budd AF, Stemann TA, Johnson KG (1994) Stratigraphic distributions of genera and species of Neogene to Recent Caribbean reef corals. J Paleontol 68:951-977

Budd AF, Nunes FLD, Weil E, Pandolfi JM (2012) Polymorphism in a common Atlantic reef coral (Montastraea cavernosa) and its long-term evolutionary implications. Evol Ecol 26:265-290

Carlon DB, Budd AF (2002) Incipient speciation across a depth gradient in a scleractinian coral? Evolution 56:2227-2242

Carstens BC, Dewey T (2010) Species delimitation using a combined coalescent and information-theoretic approach: An example from North American Myotis bats. Syst Biol 59:400-414

Chornesky EA, Peters EC (1987) Sexual reproduction and colony growth in the scleractinian coral Porites astreoides. Biol Bull 172:161-177

Concepcion G, Crepeau M, Kahng SE, Toonen RJ (2008) An alternative to ITS, a hypervariable, single-copy nuclear intron in corals, and its use in detecting cryptic species within the octocoral genus Carijoa. Coral Reefs 27:323-336

Drummond AJ, Rambaut A (2007) BEAST: Bayesian evolutionary analysis by sampling trees. BMC Evol Biol 7:214

Earl D, vonHoldt E (2011) STRUCTURE HARVESTER: a website and program for visualizing STRUCTURE output and implementing the Evanno method. Conserv Genet Resour 4:359-361

Edwards SV (2009) Is a new and general theory of molecular systematics emerging? Evolution 63:1-19 
Ellegren H (2007) Molecular evolutionary genomics of birds. Cytogenet Genome Res 117:120-130

Evanno G, Regnaut S, Goudet J (2005) Detecting the number of clusters of individuals using the software STRUCTURE: a simulation study. Mol Ecol 14:2611-2620

Eytan RI, Hayes M, Arbour-Reilly P, Miller M, Hellberg ME (2009) Nuclear sequences reveal mid-range isolation of an imperilled deep-water coral population. Mol Ecol 18:2375-2389

Fogarty ND, Vollmer SV, Levitan DR (2012) Weak prezygotic isolating mechanisms in threatened Caribbean Acropora corals. PLoS One 7:e30486

Forsman ZH, Barshis DJ, Hunter CL, Toonen RJ (2009) Shapeshifting corals: Molecular markers show morphology is evolutionarily plastic in Porites. BMC Evol Biol 9:45

Forsman ZH, Concepcion GT, Haverkort RD, Shaw RW, Maragos JE, Toonen RJ (2010) Ecomorph or endangered coral? DNA and microstructure reveal Hawaiian species complexes: Montipora dilatata/flabellata/turgescens \& M. patula/verrilli. PLoS One 5:e15021

Fukami H, Budd AF, Levitan DR, Jara J, Kersanach R, Knowlton N (2004a) Geographical differences in species boundaries among members of the Montastraea annularis complex based on molecular and morphological markers. Evolution 58:324-337

Fukami H, Budd AF, Paulay G, Solé-Cava A, Chen CA, Iwao K, Knowlton N (2004b) Conventional taxonomy obscures deep divergence between Pacific and Atlantic corals. Nature 427:832-835

Glynn PW (1973) Ecology of a Caribbean coral reef. The Porites reef-flat biotype: Part I. Meteorology and hydrography. Mar Biol 20:297-318

Guindon S, Dufayard J-F, Lefort V, Anisimova M, Hordijk W, Gascuel O (2010) New algorithms and methods to estimate maximum-likelihood phylogenies: assessing the performance of PhyML 3.0. Syst Biol 59:307-321

Hedrick PW (2005) A standardized genetic differentiation measure. Evolution 59:1633-1638

Heled J, Drummond A (2010) Bayesian inference of species trees from multilocus data. Mol Biol Evol 27:570-580

Hellberg ME (2006) No variation and low synonymous substitution rates in coral mtDNA despite high nuclear variation. BMC Evol Biol 6:24

Hey J, Wakeley J (1997) A coalescent estimator of the population recombination rate. Genetics 145:833-846

Ho SYW, Phillips MJ (2009) Accounting for calibration uncertainty in phylogenetic estimation of evolutionary divergence times. Syst Biol 58:367-380

Humann P (1993) Reef coral identification. New World Pubns, Jacksonville, FL

Huelsenbeck JP, Andolfatto P, Huelsenbeck ET (2011) Structurama: Bayesian inference of population structure. Evol Bioinform 7:55-59

Jackson JAC, Baker S, Vant M, Steel DJ, Medrano-Gonzalez L, Palumbi SR (2009) Big and slow: phylogenetic estimates of molecular evolution in baleen whales (Suborder: Mysticeti). Mol Biol Evol 26:2427-2440

Jameson SC (1997) Morphometric analysis of the Poritidae (Anthozoa: Scleractinia) off Belize. Proc 8th Int Coral Reef Symp 2:1591-1596

Jameson SC, Cairns SD (2012) Neotypes for Porites porites (Pallas, 1766) and Porites divaricata Le Sueur, 1820 and remarks on other western Atlantic species of Porites (Anthozoa: Scleractinia). Proc Biol Soc Wash 125:189-207

Keshavmurthy S, Yang SY, Alamaru A, Chuang YY, Pichon M, Obura D, Fontana S, De Palmas S, Stefani F, Benzoni F, MacDonald A, Noreen AME, Chen CS, Wallace CC, Pillay RM, Denis V, Amri AY, Reimer JD, Mezaki T, Sheppard C, Loya Y, Abelson A, Mohammed MS, Baker AC, Mostafavi PG, Suharsono BA, Chen CA (2013) DNA barcoding reveals the coral "laboratory-rat", Stylophora pistillata, encompasses multiple identities. Sci Rep 3:1520

Knowlton N, Weil E, Weigt LA, Guzman HM (1992) Sibling species in Montastraea-annularis, coral bleaching, and the coral climate record. Science 255:330-333

Kubatko L, Carstens B, Knowles L (2009) STEM: species tree estimation using maximum likelihood for gene trees under coalescence. Bioinformatics 25:971-973

Laborel J (1969) Madréporaires et hydrocoralliaires récifaux des cotes Brésiliennes systématique, écologie, répartition verticale et géographique. Annais Institute Océanographique 47:171-229

Ladner JT, Palumbi SR (2012) Extensive sympatry, cryptic diversity and introgression throughout the geographic distribution of two coral species complexes. Mol Ecol 21:2224-2238

Leaché AD, Fujita MK (2010) Bayesian species delimitation in West African forest geckos (Hemidactylus fasciatus). Proc R Soc Lond B Biol Sci 277:3071-3077

Levitan DR, Fogarty ND, Jara J, Lotterhos KE, Knowlton N (2011) Genetic, spatial, and temporal components of precise spawning synchrony in reef building corals of the Montastraea annularis species complex. Evolution 65:1254-1270

López-Pérez RA, Reyes-Bonilla H, Budd AF, Correa-Sandoval F (2003) The taxonomic status of Porites sverdrupi, an endemic coral of the Gulf of California. Cienc Mar 29:677-691

Maddison WP (1997) Gene trees in species trees. Syst Biol 46:523-536

McCormack JE, Heled J, Delaney KS, Peterson AT, Knowles LL (2011) Calibrating divergence times on species tree versus gene trees: Implications for speciation history of Aphelocoma jays. Evolution 65:184-202

Meirmans PG, Van Tienderen PH (2004) GENOTYPE and GENODIVE: two programs for the analysis of genetic diversity of asexual organisms. Mol Ecol Notes 4:792-794

Milne I, Wright F, Rowe G, Marshall D, Husmeier D, McGuire G (2004) TOPALi: software for automatic identification of recombinant sequences within DNA multiple alignments. Bioinformatics 20:1806-1807

Neigel JE, Avise JC (1986) Phylogenetic relationships of mitochondrial DNA under various demographic models of speciation. In: Karlin S, Nevo E (eds) Evolutionary processes and theory. Academic Press, New York

Nunes F, Norris RD, Knowlton N (2009) Implications of isolation and low genetic diversity in peripheral populations of an amphiAtlantic coral. Mol Ecol 18:4283-4297

Nylander JAA (2004) MrAIC. Program distributed by the author, Evolutionary Biology Centre, Uppsala University

Palumbi SR, Vollmer S, Romano S, Oliver T, Ladner J (2011) The role of genes in understanding the evolutionary ecology of reef building corals. Evol Ecol 26:317-335

Paz-García DA, Reyes-Bonilla H, Hernández-Cortés MP (2008) Genetic variation in two morphotypes of Porites panamensis from the Gulf of California, Mexico. Proc 11th Int Coral Reef Symp 1:444-448

Pinzón JH, Sampayo E, Cox E, Chauka LJ, Chen CA, Voolstra CR, LaJeunesse T (2013) Blind to morphology: genetics identifies several widespread ecologically common species and few endemics among Indo-Pacific cauliflower corals (Pocillopora, Scleractinia). J Biogeogr 40:1595-1608

Prada C, Hellberg ME (2013) Long pre-reproductive selection and divergence by depth in a Caribbean candelabrum coral. Proc Natl Acad Sci USA 110:3961-3966

Prada C, Schizas NV, Yoshioka PM (2008) Phenotypic plasticity or speciation? A case from a clonal marine organism. BMC Evol Biol 8:47

Potts DC, Done TJ, Isdale PJ, Fisk DA (1985) Dominance of a coral community by the genus Porites (Scleractinia). Mar Ecol Prog Ser 23:79-84 
Pritchard JK, Stephens M, Donnelly P (2000) Inference of population structure using multilocus genotype data. Genetics 155:945-959

Rambaut A, Drummond AJ (2007) http://beast.bio.ed.ac.uk/Tracer

Rittmeyer EN, Austin CC (2012) The effects of sampling on delimiting species from multi-locus sequence data. Mol Phylogenet Evol 65:451-463

Schlöder C, Guzman HM (2008) Reproductive patterns of the Caribbean coral Porites furcata (Anthozoa, Scleractinia, Poritidae) in Panama. Bull Mar Sci 82:107-117

Schmidt-Roach S, Lundgren P, Millwer KJ, Gerlach G, Noreen AME, Andreakis N (2013) Assessing hidden species diversity in the coral Pocillopora damicornis from Eastern Australia. Coral Reefs 32:161-172

Smith SA, Donoghue MJ (2008) Rates of molecular evolution are linked to life history in flowering plants. Science 322:86-89

Soong K (1993) Colony size as a species character in massive reef corals. Coral Reefs 12:77-83

Stake JL (2007) Novel molecular markers for phylogenetic studies of scleractinian corals. $\mathrm{Ph}$. D. thesis. University of Louisiana at Lafayette, p 165

Stefani F, Benzoni F, Yang S-Y, Pichon M, Galli P, Chen CA (2011) Comparison of morphological and genetic analyses reveals cryptic divergence and morphological plasticity in Stylophora (Cnidaria, Scleractinia). Coral Reefs 30:1033-1049

Stolting KN, Nipper R, Lindtke D, Caseys C, Waeber S, Castiglione S, Lexer C (2013) Genomic scan for single nucleotide polymorphisms reveals patterns of divergence and gene flow between ecologically divergent species. Mol Ecol 22:842-855
Todd PA (2008) Morphological plasticity in scleractinian corals. Biol Rev 83:315-337

Turner TL, Hahn MW, Nuzhdin SV (2005) Genomic islands of speciation in Anopheles gambiae. PLoS Biol 3:e285

Vollmer SV, Palumbi SR (2004) Testing the utility of internally transcribed spacer sequences in coral phylogenetics. Mol Ecol 13:2763-2772

Voolstra C, Sunagawa S, Matz M, Bayer T, Aranda M, Buschiazzo E, DeSalvo M, Lindquist E, Szmant A, Coffroth M, Medina M (2011) Rapid evolution of coral proteins responsible for interaction with the environment. PLoS One 6:e20392

Wallace CC (1999) Staghorn corals of the world: a revision of the coral genus Acropora (Scleractinia; Astrocoeniina; Acroporidae) worldwide, with emphasis on morphology, phylogeny and biogeography. CSIRO Press, Collingwood, Victoria, Australia

Weil E (1992) Genetic and morphological variation in Caribbean and eastern Pacific Porites (Anthozoa, Scleractinia). Preliminary results. Proc 7th Int Coral Reef Symp 2:643-655

Willis BL, Babcock RC, Harrison PL, Wallace CC (1997) Experimental hybridization and breeding incompatibilities within the mating system of mass spawning reef corals. Coral Reefs 16:S53-S65

Yang Z, Rannala B (2010) Bayesian species delimitation using multi locus sequence data. Proc Natl Acad Sci USA 107:9264-9269

Zlatarski VN (1990) Porites colonensis, a new species of stony coral (Anthozoa: Scleractinia) off the Caribbean coast of Panama. Proc Biol Soc Wash 103:257-264 